\title{
Determination of Titanium and Vanadium in Ziegler-Natta Catalysts by Inductively Coupled Plasma Atomic Emission Spectrometry
}

\author{
Cristiane F. Petry, Larissa B. Capeletti, Fernanda C. Stedile, João H. Z. dos Santos, and \\ Dirce Pozebon ${ }^{\dagger}$
}

Instituto de Química, Universidade Federal do Rio Grande do Sul, Av. Bento Gonçalves, 9500, 91500-790, Porto Alegre, RS, Brazil

\begin{abstract}
A method for the determination of $\mathrm{Ti}$ and $\mathrm{V}$ using inductively coupled plasma atomic emission spectrometry (ICP OES) in Ziegler-Natta polymerization catalysts is proposed. The concentrations of both $\mathrm{Ti}$ and $\mathrm{V}$ are efficiently determined after catalyst acid digestion with a mixture of $\mathrm{HNO}_{3}+\mathrm{HCl}+\mathrm{HF}$ and heating $\left(160^{\circ} \mathrm{C}\right.$ for $6 \mathrm{~h}$ ) or with $10 \%(\mathrm{v} / \mathrm{v}) \mathrm{H}_{2} \mathrm{SO}_{4}$ and heating $\left(160^{\circ} \mathrm{C}\right.$ for $6 \mathrm{~h}$ ) or with $10 \%(\mathrm{v} / \mathrm{v}) \mathrm{H}_{2} \mathrm{SO}_{4}$ and sonication (during $2 \mathrm{~min}$ ). The $\mathrm{V}$ and Ti detection limits are $0.002 \%$ and $0.08 \%$, respectively, using $0.20 \mathrm{~g}$ of catalyst sample in $50 \mathrm{ml}$. The method is validated by a comparison with the Rutherford backscattering spectrometry (RBS) technique. In this case, catalyst samples are only pressed as pellets before analyte determination. Despite the fact that both the $\mathrm{V}$ and Ti concentrations cannot be determined individually by means of RBS, because the atomic numbers of $\mathrm{Ti}$ and $\mathrm{V}$ are very close, the sum of the $\mathrm{V}$ and $\mathrm{Ti}$ contents is in accordance with that attained by means of ICP OES. According to scanning electron microscopy-energy dispersive X-ray analysis (SEM-EDX) it is observed that the Ti distribution on the catalyst grain is not homogenous.
\end{abstract}

(Received October 25, 2005; Accepted February 27, 2006)

\section{Introduction}

Ziegler-Natta catalysts are largely employed in industrial processes for the polymerization of $\alpha$-olefins in order to produce materials, such as polyethylenes and polypropylenes. The main constituents of such catalysts are $\mathrm{Ti}$ and $\mathrm{V}$, which are responsible for the catalytic activity, as a result of the immobilization of compounds, such as $\mathrm{TiCl}_{4}$ or $\mathrm{VCl}_{3}$, onto $\mathrm{MgCl}_{2}$ or $\mathrm{SiO}_{2}$ supports. ${ }^{1}$

Catalyst properties and metal content are dependent on some experimental parameters, such as the order of catalyst addition to the support, the grafting time and temperature, the molar ratio among the catalyst and the cocatalyst (aluminum compounds, such as tributylaluminum). These parameters may affect the catalyst performance in the polymerization reaction as well as the properties of the attained polymers. Therefore, the catalyst metal content is an important parameter for evaluating the catalyst performance in terms of the activity, which is defined as the capacity of the catalyst to convert the feedstock into products. The activity is expressed as the ratio of the attained product by the mass of the catalyst, which is expressed as moles of metal. The determination of the metal content in catalysts can be carried out by various techniques, ${ }^{2}$ but and in the case of Ziegler-Natta $(\mathrm{ZN})$ catalysts, Ti and $\mathrm{V}$ are usually determined by molecular absorption spectrometry after reactions with $\mathrm{H}_{2} \mathrm{O}_{2}$ and $\mathrm{H}_{2} \mathrm{SO}_{4}$ and measurements at $410 \mathrm{~nm}$ and $450 \mathrm{~nm}$, respectively. ${ }^{3-8}$ The major drawbacks of this technique are a low sampling throughput and high sample handling. In some

$\dagger$ To whom correspondence should be addressed.

E-mail: dircepoz@iq.ufrgs.br studies, $\mathrm{Ti}$ or $\mathrm{V}$ was also determined by flame atomic absorption spectrometry (FAAS) ${ }^{9-11}$ and inductively coupled plasma atomic emission spectrometry (ICP OES). ${ }^{12}$ In the case of FAAS, the limit of detection (LOD) is not very good, since V and Ti may form compounds that are not completely destroyed in the flame, while in the case of ICP OES, the persistence of such compounds would be very unlikely due to the plasma temperature. However, despite the fact that ICP OES seems to be an appropriate technique, it has not usually been employed in $\mathrm{ZN}$ catalysts analysis.

It is claimed that the major drawbacks of the above-mentioned techniques are the need for metal extraction from the bulk of the sample matrix, or sample decomposition with an acidic solution (acid digestion) prior to the analyte measurement. These procedures may be tedious, time-consuming and engender some systematic errors due to poor analyte extraction efficiency and solubility. It is expected that such problems may be overcome by using direct analysis techniques, which allow the analysis of solid samples without any analyte extraction or decomposition.

Many techniques can provide direct metal determination in catalysts, differing in the measurement principle. Particularly in the case of the Ziegler-Natta catalyst, one can mention metal content determination by $\mathrm{X}$-ray fluorescence spectrometry $(\mathrm{XRF}),{ }^{13,14}$ X-ray photoelectron spectroscopy (XPS), ${ }^{12-15}$ and Rutherford backscattering spectrometry (RBS). ${ }^{16,17}$ Indeed, in the case of XPS and RBS, which are non-relative measurement techniques, calibration may not be necessary, and the results are expressed as atomic ratios. However, it is important to mention that when the RBS and XPS techniques are used, the spatial resolution and probing depth inside the sample may vary, compromising precision and accuracy. Besides, since the catalyst is analyzed as bulk, a matrix effect due to non- 
Table 1 Instrumental conditions and parameters

$\begin{array}{ll}\text { Plasma power } & 1300 \mathrm{~W} \\ \text { Plasma gas flow } & 151 \mathrm{~min}^{-1} \\ \text { Auxiliary gas flow } & 0.21 \mathrm{~min}^{-1} \text { for } \mathrm{V} \text { and } 0.11 \mathrm{~min}^{-1} \text { for Ti } \\ \text { Nebulizer gas flow } & 0.71 \mathrm{~min}^{-1} \text { for } \mathrm{V} \text { and } 0.81 \mathrm{~min}^{-1} \text { for Ti } \\ \text { Plasma view } & \text { Axial } \\ \text { Solution flow rate } & 1.20 \mathrm{ml} \mathrm{min}-1 \\ \text { Injector } & \text { Alumina }(2 \mathrm{~mm} \mathrm{i.d.)} \\ \text { Nebulizer } & \text { Pneumatic }(\mathrm{GemCone}) \\ \text { Spray chamber } & \text { Scott }(\text { Ryton } \\ \text { Processing mode } & \text { Area }(7 \text { points per peak) } \\ \text { Replicates } & 2 \\ \text { Background correction } & 2 \text { points } \\ \text { Emission lines } & \text { V(I) } 292.464 \text { nm and Ti(I) } 336.121 \mathrm{~nm}\end{array}$

homogeneity can hinder accurate metal determination, which is the case of XRF. In addition, the calibration in XRF may be a concern, since it is necessary to produce solid standards having composition similar to the catalyst.

The main purpose of the present work is to develop a methodology for $\mathrm{Ti}$ and $\mathrm{V}$ determination in supported $\mathrm{ZN}$ catalysts containing both metal centers, using ICP OES. Different sample preparation procedures are evaluated in terms of better metal extractions. For method validation, the catalyst samples are also analyzed by means of RBS. The metal distribution on the catalyst grain is evaluated by scanning electron microscopy-energy dispersive X-ray analysis (SEMEDX).

\section{Experimental}

Inductively coupled plasma atomic emission spectrometry (ICP $O E S$ )

An inductively coupled plasma optical emission spectrometer from Perkin Elmer (Optima 2000 DV) was used. Argon $(99.996 \%)$ was used as the auxiliary, nebulizer and plasma gas, nitrogen (99.996\%) was used as the purge gas of the optical system; compressed air was used as chear gas. The instrumental conditions and parameters are summarized in Table 1. An ultrasonic processor (Homogeneizador Ultrasônico Computadorizado, Unique Brazil) equipped with a $\phi$ 4-mm titanium tip was used for catalyst sample slurry sonication.

Chemical reagents and materials. All chemical reagents were of analytical grade. Ultrapure water (resistivity of $18.2 \mathrm{M} \Omega$ $\mathrm{cm}^{-1}$ ) from a Milli-Q ${ }^{\circledR}$ purifier system (Millipore Corp., Bedford, MA, USA) was used; $65 \%(\mathrm{~m} / \mathrm{m}) \mathrm{HNO}_{3}, 37 \%(\mathrm{~m} / \mathrm{m})$ $\mathrm{HCl}, 40 \%(\mathrm{~m} / \mathrm{m}) \mathrm{HF}$ and $98 \%(\mathrm{~m} / \mathrm{m}) \mathrm{H}_{2} \mathrm{SO}_{4}$ (Merck, Darmstadt, Germany) were used. Calibration solutions ranging from 1.0 to $5.0 \mathrm{mg}^{-1}$ of $\mathrm{V}$ and $\mathrm{Ti}$ were prepared fresh daily in $7 \%(\mathrm{v} / \mathrm{v})$ $\mathrm{HNO}_{3}$ or $5 \%$ (v/v) $\mathrm{H}_{2} \mathrm{SO}_{4}$, from $1000 \mathrm{mg} \mathrm{l}^{-1}$ single-element solutions of Ti or V (Titrisol ${ }^{\circledR}$, Merck).

The analyzed Ziegler-Natta catalyst samples were prepared according to the literature. ${ }^{1}$ Polymerization catalysts were based on $\mathrm{Ti}$ and $\mathrm{V}$ chloride, supported on silica chemically modified with an organomagnesium compound. The supported catalysts differed concerning the preparative conditions (grafting time and temperature as well as $\mathrm{Ti}$ and $\mathrm{V}$ molar ratio) and, therefore, on the final metal content. The preparative conditions were expressed in terms of the $\mathrm{Ti}$ and $\mathrm{V}$ molar ratio due to confidentiality.

Sample preparation. Five procedures were investigated by
Table 2 Titanium and $\mathrm{V}$ concentrations in $\mathrm{ZN}$ catalyst determined by ICP OES using different procedures for sample preparation

\begin{tabular}{cll}
\hline Procedure & $\mathrm{Ti}, \%(\mathrm{~m} / \mathrm{m})$ & $\mathrm{V} / \mu \mathrm{g} \mathrm{g}^{-1}$ \\
\hline 1 & $0.98 \pm 0.019$ & $487 \pm 5$ \\
2 & $1.00 \pm 0.037$ & $500 \pm 9$ \\
3 & $0.96 \pm 0.019$ & $480 \pm 7$ \\
4 & $0.83 \pm 0.030$ & $403 \pm 4$ \\
5 & $0.80 \pm 0.008$ & $418 \pm 20$ \\
\hline
\end{tabular}

The uncertainties are the standard deviations of 3 determinations (analysis in triplicate).

using sample decomposition, or analyte extraction as follows: (1) 0.02 to $0.200 \mathrm{~g}$ of the catalyst sample was weighed and placed into a PTFE vessel (made of Teflon ${ }^{\circledR}$ ) to which $3.5 \mathrm{ml}$ $\mathrm{HNO}_{3}+3 \mathrm{ml} \mathrm{HF}+1.5 \mathrm{ml} \mathrm{HCl}$ were added. ${ }^{18}$ Subsequently, the vessel was capped and placed on a heating block at a temperature of $160^{\circ} \mathrm{C}$ for $6 \mathrm{~h}$. Afterwards, the heating block was turned off and the sample solution was left standing to reach room temperature. Then, the PTFE vessel was opened and the attained sample solution (absence of residues) was transferred to a graduated polypropylene flask that was filled up to a volume of $50 \mathrm{ml}$. (2) A similar procedure as described in (1) was carried out in (2), with the exception of the acid mixture, which was only $4 \mathrm{ml}$ of $10 \%$ (v/v) $\mathrm{H}_{2} \mathrm{SO}_{4}$ in (2), ${ }^{1}$ which promoted complete sample decomposition (absence of residues). (3) 0.02 to $0.200 \mathrm{~g}$ of sample was weighed and transferred to a graduated polypropylene flask to which $4 \mathrm{ml}$ of $10 \%$ (v/v) $\mathrm{H}_{2} \mathrm{SO}_{4}$ was added. Subsequently, the volume of the attained slurry was completed to $25 \mathrm{ml}$, and then sonicated for 2 min at $80 \mathrm{~W}$. After the sonication procedure, water was added to the flask and the volume was completed to $50 \mathrm{ml}$. Then, the sample slurry (large amount of residues) was centrifuged for 2 min at $2700 \mathrm{rpm}$, and the analyte was measured in the supernatant. (4) Almost similar procedures as described in (3) were investigated in (4) and (5), but in these cases the sample was only left in contact with a $10 \%(\mathrm{v} / \mathrm{v}) \mathrm{H}_{2} \mathrm{SO}_{4}$ solution overnight in procedure (4), or in a mixture made of $3.5 \mathrm{ml}$ $\mathrm{HNO}_{3}+3 \mathrm{ml} \mathrm{HF}+1.5 \mathrm{ml} \mathrm{HCl}$ in procedure (5). Catalysts samples did not completely solubilize in procedures (4) and (5), and they were also centrifuged as in procedure (3). When $\mathrm{HNO}_{3}$ was used, the sample solution volume was completed up to $50 \mathrm{~mL}$ by water addition (the final $\mathrm{HNO}_{3}$ concentration was about $7 \% \mathrm{v} / \mathrm{v}$ ). When $10 \%(\mathrm{v} / \mathrm{v}) \mathrm{H}_{2} \mathrm{SO}_{4}$ was used, the sample volume was then completed to $50 \mathrm{ml}$ by adding a $10 \%(\mathrm{v} / \mathrm{v})$ $\mathrm{H}_{2} \mathrm{SO}_{4}$ solution. Vanadium and Ti were directly measured in sample solutions attained according the above procedures without any further dilution, or the sample solution was tentimes diluted with water. External calibration was used throughout the analysis; the $\mathrm{HNO}_{3}$ or $\mathrm{H}_{2} \mathrm{SO}_{4}$ concentration in the calibration solutions was the same as in the final sample solution.

\section{Rutherford backscattering spectrometry (RBS)}

Metal loading in catalysts was determined by RBS using $\mathrm{He}^{+}$ beams of $2.0 \mathrm{MeV}$ incidents on tablets that were prepared by pressing (12 $\mathrm{MPa})$ the sample powder. During analysis, the pressure in the chamber was kept at about $10^{-7}$ mbar by using a membrane (to prevent oil contamination of the sample) and a turbo drag molecular pump. The method is based on the atomic number and the determination of the energy of the detected particles, which are elastically scattered in the Coulombic field 
Table 3 Titanium and V concentrations determined by ICP OES in the catalysts samples and $\mathrm{Ti}+\mathrm{V}$ concentration determined by RBS

\begin{tabular}{cccc}
\hline $\begin{array}{c}\text { Ziegler-Natta } \\
\text { catalyst }\end{array}$ & $\mathrm{Ti}, \%(\mathrm{~m} / \mathrm{m})$ & $\mathrm{V}, \%(\mathrm{~m} / \mathrm{m})$ & $\begin{array}{c}\mathrm{M} / \mathrm{SiO}_{2}, \\
\%(\mathrm{~m} / \mathrm{m})^{\mathrm{a}}\end{array}$ \\
\hline ZN1 & 0.84 & 0.07 & 0.95 \\
$\mathrm{ZN2}$ & 0.73 & 0.03 & 0.70 \\
$\mathrm{ZN3}$ & 1.00 & 0.05 & 1.03 \\
$\mathrm{ZN4}$ & 1.17 & 0.03 & 1.11 \\
$\mathrm{ZN5}$ & 0.36 & 0.14 & 0.55 \\
$\mathrm{ZN6}$ & 0.36 & 0.047 & 0.44 \\
$\mathrm{ZN}^{\mathrm{b}}$ & 1.55 & nd & 1.60 \\
$\mathrm{ZN8}^{\mathrm{c}}$ & nd & 0.025 & nd \\
\hline
\end{tabular}

M, Sum of Ti + V; nd, not determined.

a. Determined by RBS.

b. Catalyst containing only $\mathrm{Ti}$.

c. Catalyst containing only V.

Concentrations of $\mathrm{V}$ and $\mathrm{Ti}$ are the medium of 3 determinations (analysis in triplicate).

of the atomic nuclei in the target. In this study, the $\mathrm{M} / \mathrm{Si}(\mathrm{M}=$ $\mathrm{V}$ or $\mathrm{Ti}$ ) atomic ratio was determined from the heights of the signals corresponding to each of the elements in the spectra, and converted to mass $\% \mathrm{M} / \mathrm{SiO}_{2}$, since it is the major constituent of the matrix, and due to confidentiality issues. For an introduction to the method and applications of this technique, the reader is referred elsewhere. ${ }^{16,17}$

Scanning electron microscopy-energy dispersive $X$-ray analysis (SEM-EDX)

The metal distribution on the catalyst grain and the elemental analysis were simultaneously studied with a Noran Instruments EDX system connected to a JEOL JSM $6300 \mathrm{~F}$ scanning electron microscopic, with $20 \mathrm{kV}$ and 60.000 times of magnification. Samples were fixed on carbon tape on a stub, followed by gold sputtering.

\section{Results and Discussion}

First of all, procedures of sample preparation were evaluated prior both $\mathrm{V}$ and Ti determination by ICP OES, using one of the analyzed samples (ZN3). This one was chosen just because it was available in higher amount than the others. The used procedures were previously described, which namely deal with: static contact of the catalyst with a mixture of concentrated acid, or diluted acid, at room temperature or under heating, or under sonication. It is worth citing that the mass of some samples used was as low as $0.020 \mathrm{~g}$ just because of the small amount available (samples were analyzed in triplicate). In addition, it was observed that the sample matrix did not interfere even if $0.200 \mathrm{~g}$ of the sample catalyst was used in a final volume of 50 $\mathrm{ml}$. According to SEM-EDX analysis, the $\mathrm{Mg}, \mathrm{Si}, \mathrm{Cl}$ and $\mathrm{Ti}$ concentrations in the attained sample solution were about 160 , 2400, 1240 and $195 \mu \mathrm{g} \mathrm{l}^{-1}$. It was observed that the Ti and V signals were not suppressed in this medium, and the background signal was well corrected. It is important to mention that $\mathrm{Cl}$ and $\mathrm{Si}$, whose concentrations are high in the final catalyst sample solution, are non easy ionizable elements, and therefore their influence was not remarkable. This means that external calibration can be employed without the need for matrix matching, excepting the acid concentration. The acid concentration $\left(7 \% \mathrm{v} / \mathrm{v} \quad \mathrm{HNO}_{3}\right.$ or $\left.10 \% \mathrm{v} / \mathrm{v} \quad \mathrm{H}_{2} \mathrm{SO}_{4}\right)$ in the

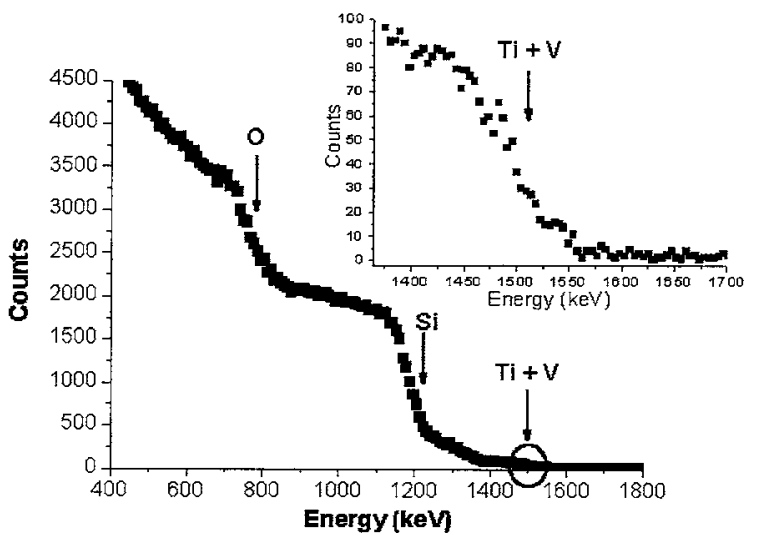

Fig. 1 Typical RBS spectrum of a ZN catalyst system supported on $\mathrm{SiO}_{2}$.

calibration solutions was almost the same as in the final sample solution, which corrected for any sample uptake and the efficiency of sample introduction in the plasma. The concentrations of $\mathrm{V}$ and $\mathrm{Ti}$ in $\mathrm{ZN} 3$, which was prepared by means of different procedures are given in Table 2 .

As can be seen in Table 2, almost similar concentrations of $\mathrm{V}$ and $\mathrm{Ti}$ are found by employing procedures (1), (2) and (3), in which heating or sonication is used. However, procedure (2), in which $10 \%(\mathrm{v} / \mathrm{v}) \mathrm{H}_{2} \mathrm{SO}_{4}$ and heating are used, seems to be the most efficient one. The efficiency of this sample-preparation procedure is also in accordance with previous work, which reported that it used $\mathrm{H}_{2} \mathrm{SO}_{4}$ and heating to decompose commercial supported Ziegler-Natta catalysts for the determination of $\mathrm{Ti}$ and $\mathrm{Mg}$ using molecular absorption spectrometry. ${ }^{14}$ It is supposed that the best metal recovery is due to the complete dissolution of $\mathrm{V}$ and $\mathrm{Ti}$ compounds by $\mathrm{H}_{2} \mathrm{SO}_{4}$. However, according to Table 2, there is no significant differences $(P<0.05)$ between procedures (1), (2) and (3); all three are recommended. This means that very simple procedures, such as the addition of $10 \%(\mathrm{v} / \mathrm{v}) \mathrm{H}_{2} \mathrm{SO}_{4}$ and sonication, or heating can be used for $\mathrm{V}$ and Ti determination in catalysts based on $\mathrm{Ti}$ and $\mathrm{V}$ chloride supported on silica, by means of ICP OES. In procedures (4) and (5), despite the good precision, $\mathrm{Ti}$ and $\mathrm{V}$ are not completely extracted, and it seems that a definite part of $\mathrm{V}$ and $\mathrm{Ti}$ are only released if the catalyst sample is completely decomposed, or extracted by sonication. In the present work, procedure (2) was further used to prepare the catalysts samples ZN1, ZN2, ZN4, ZN5, ZN6, ZN7 and $\mathrm{ZN} 8$ because it gives the best results for both $\mathrm{Ti}$ and $\mathrm{V}$, and only $10 \%(\mathrm{v} / \mathrm{v}) \mathrm{H}_{2} \mathrm{SO}_{4}$ is added to the sample.

The aforementioned catalyst samples were also analyzed by means of RBS, and the typical spectrum is shown in Fig. 1. The plateaus of $\mathrm{O}, \mathrm{Si}$, Ti and $\mathrm{V}$ can be observed, but those of Ti and $\mathrm{V}$ cannot be distinguished because the atomic masses of $\mathrm{V}$ and Ti are close enough to hamper the atom pair resolution. Thus, the contents of $\mathrm{V}$ and Ti can only be seen as the sum of both elements, which may be expressed in terms of $\mathrm{M} / \mathrm{SiO}_{2}$, where $\mathrm{M}$ represents the sum of both $\mathrm{V}$ and $\mathrm{Ti}$. The resulting $\mathrm{M}$ concentrations in the investigated catalysts, determined by RBS, are given in Table 3 together with the $\mathrm{V}$ and Ti concentrations obtained from ICP OES. In Table 3 it is possible to observe that the sums of $\mathrm{Ti}$ and $\mathrm{V}$ agree very well, which demonstrates the accuracy of the data attained by using ICP OES. The concentration of $\mathrm{M}(\mathrm{Ti}+\mathrm{V})$ was not determined by RBS in the catalyst ZN8, since it could not be detected. According to Table 3 , the grafted metal content in the supported Ziegler-Natta 


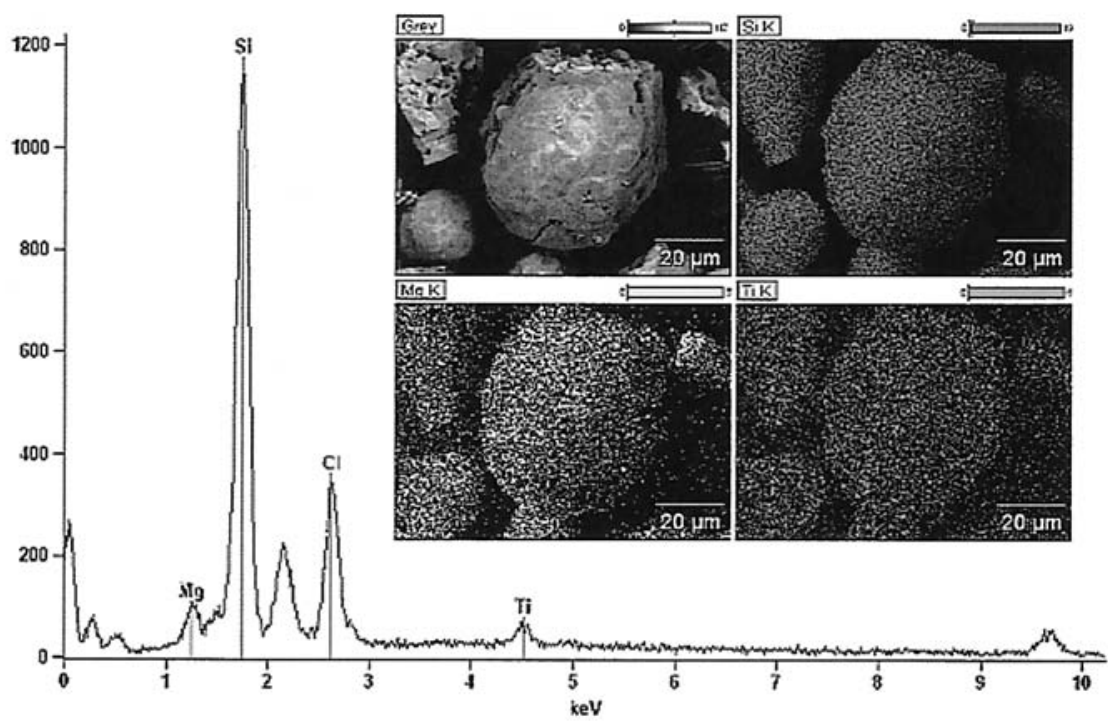

Fig. 2 SEM-EDX spectrum of the ZN3 catalyst. Insert: $\mathrm{Mg}$, Si and $\mathrm{Ti}$ distribution on the ZN catalyst grain. Note the inhomogeneity of the grain and the element distribution. Vanadium is not detected.

catalysts ranges from 0.4 to $1.6 \%(\mathrm{~m} / \mathrm{m})$, for which the highest concentration is in the catalyst bearing only the $\mathrm{Ti}$ species (ZN7).

The V and Ti detection limits (LODs) of the ICP OES method (using axial plasma view) ${ }^{19}$ were determined from $3 s, s$ being the standard deviation of 10 consecutive runs of the sample blank (only the reagents submitted to the same procedure as the sample). Taken in consideration of a sample mass aliquot of $0.200 \mathrm{~g}$ in $50 \mathrm{ml}$, the $\mathrm{V}$ and Ti LODS (including the whole procedure) were $0.002 \%$ and $0.08 \%$, respectively. These values compare well with those of RBS, which are normally achieved for high- $Z$ elements, the LODS of which are in the range of $0.01 \%$. However, the LODs in RBS may be worsened because they are dependent on many experimental parameters, such as Z (atomic number), energy of the beam particles, fraction of backscattered particles, and density of the matrix and alignment of the ion beam.

Although the sum of the total metal content $(\mathrm{Ti}+\mathrm{V})$ can provide important information, which enables one to estimate the productivity of such a catalyst system, two catalyst centers (Ti and V) are used to generate distinct surface catalyst species, which will produce polymers with different properties, namely the weight-average molecular weight and the polydispersity. Therefore, the specific determination of both $\mathrm{Ti}$ and $\mathrm{V}$ is an important issue, since it can provide an insight into the effect of each species in terms of the catalyst activity and the polymer properties. Consequently, ICP OES is more suitable for the determination of these elements in $\mathrm{ZN}$ catalysts, in spite of the simplicity and sample throughput of RBS, a direct analysis technique.

In order to evaluate the distribution of metals in the catalyst particle, SEM-EDX analysis was performed. Figure 2 shows a typical spectrum, indicating the presence of $\mathrm{Mg}, \mathrm{Si}, \mathrm{Cl}$ and $\mathrm{Ti}$ in the $\mathrm{ZN} 3$ sample. The corresponding atomic percentage was, respectively, $4.05,60.12,30.96$ and $4.87 \%$. Due to the measurement principle and the variation of the probe depth inside the sample, these results are not quantitative and not directly comparable to those determined with the use of RBS or ICP OES, since only the uttermost external catalyst surface has been measured in the case of SEM-EDX.
According to Fig. 2, the Ti distribution on the catalyst grain is not completely uniform, which may be a constraint in the analysis by RBS, since the sample bulk is directly analyzed. However, because the catalyst powder is pressed as a pellet, the analyzed sample is more homogeneous, compensating for the eventual heterogeneity of the catalyst particle. The presence of $\mathrm{V}$ could not be observed due to its low concentration in the catalyst.

It is concluded that $\mathrm{V}$ and $\mathrm{Ti}$ can be determined by means of ICP OES with no major difficulties. It was observed that matrix matching is not necessary and simple external calibration can be used, when up to $0.200 \mathrm{~g}$ of a sample in $50 \mathrm{ml}$ final solution is used. Sample preparation is easy, the detection limits are favorable and the sample throughput is good. The methodology of sample preparation as well as the technique may be recommended for the determinations of other elements in $\mathrm{ZN}$ catalysts. In the case of RBS, a direct analysis technique, Ti and $\mathrm{V}$ cannot be separated and determined individually. The major drawback of the technique for quantitative analysis is the closeness of the atomic number of the involved elements.

\section{Acknowledgements}

The authors acknowledge Conselho Nacional de Desenvolvimento Científico e Tecnológico (CNPq).

\section{References}

1. B. A. Krentzel, Y. V. Kissin, V. I. Kleiner, and L. L. Stotskaya, "Polymers and Copolymers of Higher $\alpha$ Olefins", 1997, Chap. 1, Hanser, Munich.

2. J. M. Thomas and W. J. Thomas, "Principles and Practice of Heterogeneous Catalysis", 1997, Chap. 3, Wiley, New York, $145-254$.

3. A. Sharlani, J. C. Hsu, and D. W. Bacon, in "Progress and Development of Catalytic Olefin Polymerization", ed. T. Sano, T. Uozumi, H. Nakatani, and M. Terano, 2002, Technology and Education Publishers, Tokyo, 53 - 64. 
4. A. Muñoz-Escalona, A. Fuentes, J. Liscano, and A Albornoz, in "Catalytic Olefin Polymerization", ed. T. Keii and K. Soga, 1990, Kodansha, Tokyo, 377 - 404.

5. M. A. S. Costa, R. A. Pereira, and F. M. B. Coutinho, Eur. Polym. J., 1999, 35, 1327.

6. G. Satyanarayana and S. Sivaram, Macromol. Rapid Commun., 1994, 15, 601.

7. S. Dumas and C. G. Hsu, J. Appl. Polym. Sci., 1989, 37 , 1605.

8. M. C. Forte and F. M. B. Coutinho, Eur. Polym. J., 1996, 32, 223.

9. H. Lee, Y.-T Jeong, and K.-K Kang, in "Catalyst Design for Tailor-Made Polyolefins", ed. K. Soga and M. Terano, 1994, Kodansha, Tokyo, 153 - 161.

10. T. T. Pakkanen, E. Vähäsarja, T. A. Pakkanen, E. Iiskola, and P. Sormunen, J. Catal., 1990, 121, 248.

11. V. D. Noto, G. Cecchin, R. Zannnetti, and M. Viviani,
Macromol. Chem. Phys., 1994, 195, 3395

12. M. M. C. Forte, F. Cunha, and J. H. Z. dos Santos, J. Mol. Catal. A: Chem., 2001, 175, 91.

13. G. Zohuri, S. Ahmadjo, R. Jamjah, and M. Nekoomanesh, Iranian Polym. J., 2001, 10, 149.

14. K. M. Bichinho, G. P. Pires, J. H. Z. dos Santos, M. M. C. Forte, and C. R. Wolf, Anal. Chim. Acta, 2004, 512, 359.

15. K. M. Bichinho, G. P. Pires, F. C. Stedile, and J. H. Z. dos Santos, Spectrochim. Acta, 2002, 57, 1877.

16. F. C. Stedile and J. H. Z. dos Santos, Nucl. Instrum Methods Phys. Res., Sect. B, 1998, 136, 1259.

17. F. C. Stedile and J. H. Z. dos Santos, Phys. Status Solidi (a), 1999, 173, 123.

18. D. Pozebon and P. Martins, At. Spectrosc., 2002, 23(4), 111.

19. C. F. Petry, D. Pozebon, and F. R. S. Bentlin, At. Spectrosc., 2005, 26(1), 19 